\title{
Molecular weight specific impact of soluble and immobilized hyaluronan on CD44 expressing melanoma cells in 3D collagen matrices
}

Jiranuwat Sapudom ${ }^{\mathrm{a}, \S}$, Franziska Ullm ${ }^{\mathrm{a}, \S}$, Steve Martin ${ }^{\mathrm{a}}$, Liv Kalbitzer ${ }^{\mathrm{a}}$, Johanna Naab ${ }^{\text {a }}$, Stephanie Möller ${ }^{\mathrm{b}}$, Matthias Schnabelrauch, ${ }^{\mathrm{b}}$ Ulf Anderegg ${ }^{\mathrm{c}}$, Stephan Schmidt ${ }^{\mathrm{a}, \mathrm{d}}$, Tilo Pompe ${ }^{\mathrm{a}, *}$

${ }^{\text {a }}$ Institute of Biochemistry, Faculty of Biosciences, Pharmacy and Psychology, Universität Leipzig, Leipzig 04103, Germany

${ }^{\mathrm{b}}$ INNOVENT e. V., Biomaterials Department, Prüssingstraße 27B, 07745 Jena, Germany

${ }^{c}$ Department of Dermatology, Venerology and Allergology, Universitätsklinikum Leipzig, Leipzig 04103, Germany

${ }^{d}$ Heinrich-Heine-Universität, Institute for Organic and Macromolecular Chemistry, Universitätsstrasse 1, 40225 Düsseldorf, Germany

$\S$ Authors contributed equally to this work

* To whom correspondence should be addressed:

Tilo Pompe

Postal address: $\quad$ Universität Leipzig

Institute of Biochemistry

Johannisallee 21-23

04103 Leipzig

Germany

Phone/Fax: $\quad$ +493419736931/9

Email: $\quad$ tilo.pompe@uni-leipzig.de

This article was published in final edited form as:

Sapudom J, Ullm F, Martin S, Kalbitzer L, Naab J, Moller S, Schnabelrauch M, Anderegg U, Schmidt S, Pompe T. Molecular weight specific impact of soluble and immobilized hyaluronan on CD44 expressing melanoma cells in 3D collagen matrices. Acta Biomater 50:259-70 (2017). 


\begin{abstract}
Hyaluronan (HA) and its principal receptor CD44 are known to be involved in regulating tumor cell dissemination and metastasis. It is hypothesized that the CD44-HA interaction regulates proliferation and invasion of tumor cells in dependence on the molecular weight and the presentation form of HA. To address this hypothesis, we reconstituted 3D collagen (Coll I) matrices and functionalized them with HA of molecular weight of 30-50 kDa (low molecular weight; LMW-HA) and 500-750 kDa (high molecular weight; HMW-HA). A post-modification strategy was applied to covalently immobilize HA to reconstituted fibrillar Coll I matrices, resulting in a non-altered Coll I network microstructure and stable immobilization over days. Functionalized Coll I matrices were characterized regarding topological and mechanical characteristics as well as HA amount using confocal laser scanning microscopy, colloidal probe force spectroscopy and quantitative Alcian blue assay, respectively. To elucidate tumor cell behavior, BRO melanoma cell lines with and without CD44 receptor expression were used for in vitro cell experiments. We demonstrated that only soluble LMW-HA promoted cell proliferation in a CD44 dependent manner, while HMW-HA and immobilized LMW-HA did not. Furthermore, an enhanced cell invasion was found only for immobilized LMW-HA. Both findings correlated with a very strong and specific adhesive interaction of LMW-HA and CD44+ cells quantified in single cell adhesion measurements using soft colloidal force spectroscopy. Overall, our results emphasize the importance of presentation mode and molecular weight specificity in biomaterial studies on the impact of HA on cell behavior.
\end{abstract}

\title{
Keyword:
}

extracellular matrix; hyaluronan; collagen; melanoma cells; CD44 receptor 


\section{Introduction}

Hyaluronan (HA) is ubiquitously present in the extracellular matrix (ECM) of all vertebrate tissues. Besides the widely known space-filling and lubricating properties of HA, it controls in a specific manner tissue homeostasis and biomechanical integrity, and is involved in many physiological and pathological processes [1,2]. Especially in solid tumors, the higher expression of HA is correlated with aggressive malignancy both in preclinical models and in patients $[3,4]$.

HA is a linear polysaccharide of repeating non-sulfated disaccharide units consisting of glucuronic acid and $\mathrm{N}$-acetylglucosamine. $\mathrm{HA}$ is highly charged at physiological $\mathrm{pH}$ due to the abundance of carboxyl and hydroxyl groups leading to a highly swollen and hydrated state $[5,6]$. HA synthesis occurs at the intracellular side of the cell membrane of fibroblasts and is regulated by 3 types of integral membrane proteins, namely HA synthases: HAS1, HAS2 and HAS3. Typically, HAS enzymes produce HA of different size by repeatedly adding glucuronic acid and $\mathrm{N}$-acetylglucosamine to the growing polysaccharide chain [7]. HAS enzymes usually synthesize HA of a size between 200 to $2000 \mathrm{kDa}$ at physiological conditions [8]. The degradation of HA is tightly controlled by hyaluronidases (HYAL) by hydrolyzing the glycosidic bond between the 2 subunits resulting in the production of fragments of different sizes [3]. Therefore, the regulation of HA synthesis and degradation is essential for ECM homeostasis and other biological processes. Importantly, HA molecular weight has been reported to strongly affect biological function of HA with frequently opposing effects on cellular behavior [1,911]. High molecular weight HA (HMW-HA; MW $>500 \mathrm{kDa}$; formed under homeostatic conditions) inhibits cell proliferation, acts anti-angiogenic, anti-inflammatory and immunosuppressive [12,13]. In contrast, shorter fragments of HA (i.e. low molecular weight HA (LMW-HA); MW 20 - 200 kDa) originating from HMW-HA degradation by HYAL $[1,14]$ and reactive oxygen species [15], enable cell migration, initiate angiogenesis and act pro-inflammatory and pro-angiogenic [6,9,16]. In tumor development, LMW-HA was found to be the predominant HA form in several malignant tumors [1719]. Although there exists some hypotheses for the contrasting impact of the different forms of HA on cell behavior (see below), a clear explanation is still lacking. This ongoing discussion is additionally interfered by contradicting findings for different settings of HA presentation [1,20]. Many studies (especially in vitro) use HA supplements in cell culture medium without any option and definition of its binding state to surrounding cell culture supports as is the case in vivo. This marked difference to the covalently bound state of the in vivo ECM strongly questions the significance of the impact of HA MW. Up to now the binding state of HA with different MW was hardly addressed in such studies.

Many specific biological functions of HA rely on the interaction of HA with its principal receptors CD44, receptor for HA mediated motility (RHAMM) and intercellular adhesion molecule-1 (ICAM-1). Among those receptors, CD44 is the best characterized and most prominent HA receptor and has raised strong interest concerning its impact on tumor progression and metastasis [21,22]. CD44 categorizes a huge family of transmembrane glycoproteins, belonging to the class of cell adhesion molecules [23]. It is a ubiquitous, multi-structural and multifunctional cell surface molecule. CD44 is expressed in many cell types, including fibroblasts, leukocytes, epithelial cells, keratinocytes, stem cells as well as most tumor cells. Its ability to bind HA is tightly regulated [12,24,25]. CD44 is known to be involved in many cellular processes, e.g. cell adhesion, proliferation and migration [24,26,27]. In tumor tissue, high levels of CD44 expression have been observed in numerous tumor cell types and appear to be important in tumor metastasis and development $[12,23,27]$. The mechanism of CD44-HA interaction is suggested to rely on switches of CD44 between an inactive, non-binding state and an active HAbinding state. It has been reported that the HA-binding domain of CD44 adopts 2 different conformations, resulting in high- and low-affinity states [25]. The non-binding O-state is marked by a folded C-terminal segment, which is partially disordered upon ligand binding and switching to their PDstate [28]. All transcript variants of CD44 share the same HA-binding motif in the N-terminus, whereas the alternative exons are located in the extracellular stem part of the molecule. Therefore, HA-binding 
seems to be similar for the known transcript variants. Different mechanisms of CD44-HA signaling are discussed in respect to HA MW in order to explain findings of MW dependence in cellular behavior. It has been reported, that LMW-HA directly triggers CD44 signal transduction via activation of merlin, PI3K and Erk signaling, resulting in enhanced growth, invasion and motility. Contrary, HMW-HA downregulates CD44 signaling mediators [26]. However, as mentioned above, binding state of HA to the ECM and in vitro mimicking were typically not well controlled.

The impact of the biophysical characteristics of the ECM, namely network topology, matrix stiffness as well as the 3D character has become a major issue in understanding tumor cell behavior. In order to mimic such properties in in vitro cell culture systems, several approaches using fibrillary networks from natural biopolymers (e.g. collagen type I (Coll I)), as well as hydrogels based on synthetic polymers or macroporous polymer scaffolds have been evolved as relevant models during the last decades [29-31]. Among those biomaterials collagen based matrices have the advantage to display many key characteristics of the in vivo ECM, including high abundance, fibrillar character, micrometer-sized porosity, expression of native ligands for cell receptors and other ECM molecules as well as low stiffness. Furthermore, Coll I based matrices are well known to be readily adjustable in various important ECM properties, e.g. topology [32-34], matrix modulus [35-38] and functionalization with other ECM components, including glycosaminoglycans (GAG) [39-42]. Hence, Coll I based scaffolds are suggested to be advantageous tools to study CD44-HA interaction in dependence on MW and binding status of HA and its impact of tumor cell behavior.

\section{Materials and methods}

\subsection{Polymer coating of glass coverslips}

Covalent binding of Coll I on a glass surface improves the stability and practical handling of 3D Coll I matrices. For this purpose, poly(styrene-alt-maleic anhydride) (PSMA; MW $=30000 \mathrm{~g} / \mathrm{mol}$ ) (SigmaAldrich, Steinheim, Germany) copolymer coated glass coverslips were prepared as previously reported [43]. Briefly, $13 \mathrm{~mm}$ coverslips (VWR International, Leuven, Belgium) were pre-cleaned and aminosilanized. Subsequently, coverslips were spin-coated with PSMA $(0.14 \% \mathrm{v} / \mathrm{v}$ dissolved in tetrahydrofuran) at $4000 \mathrm{rpm}$ for $20 \mathrm{~s}$. The glass coverslips were tempered for $2 \mathrm{~h}$ at $120^{\circ} \mathrm{C}$ to ensure the availability of reactive anhydride groups prior to use.

\subsection{Reconstitution of 3D Coll I matrices}

The reconstitution of 3D Coll I matrices was performed on PSMA-coated $13 \mathrm{~mm}$ glass coverslips. Coll I matrices at the concentration of $1.5,2.0$ and $2.5 \mathrm{mg} / \mathrm{ml}$ were reconstituted by mixing rat tail Coll I solution (Corning, Berlin, Germany) with phosphate buffer with an ionic strength of $250 \mathrm{mM}$ at $\mathrm{pH} 7.5$. Coll I solution was prepared on ice to inhibit early fibrillation. Subsequently, $430 \mu 1$ Coll I solution was transferred onto PSMA-coated coverslips and $400 \mu 1$ were subsequently removed (30 $\mu 1$ of Coll I solution remained on the coverslip). Coll I fibrillation was carried out at $37{ }^{\circ} \mathrm{C}, 5 \% \mathrm{CO}_{2}$ and $95 \%$ humidity for $90 \mathrm{~min}$. To prevent the matrix from drying, matrices were kept in phosphate buffer saline (PBS; Biochrom, Berlin, Germany) prior to use.

\subsection{Cross-linking of 3D Coll I matrices}

Reconstituted Coll I matrices were cross-linked with $N$-(3-Dimethylaminopropyl)- $N$ '-ethylcarbodiimide hydrochloride (EDC; Sigma-Aldrich) by incubation with $4 \mathrm{mg} / \mathrm{mL}$ EDC dissolved in $100 \mathrm{mM}$ in 2-(Nmorpholino)ethanesulfonic acid (MES; Sigma-Aldrich) at $\mathrm{pH} 5$ for $2 \mathrm{~h}$ at room temperature, as 
previously reported [44]. Subsequently, matrices were rinsed 3 times with PBS and stored in a hydrated state prior to use.

\subsection{HA immobilization into 3D Coll I matrices}

HA was covalently immobilized using EDC cross-linker, as previously reported [42]. Briefly, HA with a molecular weight of 30-50 kDA (LMW-HA) and 500-750 kDA (HMW-HA) (Contipro Biotech. s.r.o., Dolni Dobrouc, Czech Republic) was dissolved in $100 \mathrm{mM}$ MES buffer at $\mathrm{pH} 5$ at a HA concentration of $0.1 \mathrm{mg} / \mathrm{ml}$. Reconstituted 3D Coll I matrices were incubated with prepared HA solution at room temperature for $2 \mathrm{~h}$. Subsequently, HA solution was removed and EDC cross-linking solution (as described in cross-linking session) was directly added without washing. Matrices were incubated with EDC cross-linking solution for $2 \mathrm{~h}$ at room temperature and followed by washing 3 times each 5 min with PBS. Prior to cell experiments, matrices were equilibrated in cell culture medium for $1 \mathrm{~h}$.

\subsection{Quantitative analysis of topological and mechanical properties}

For the analysis of topological parameters i.e. pore size and fibril size, confocal image stacks of the Coll I matrices were acquired with a confocal laser scanning microscope 700 (cLSM 700; Carl Zeiss Microscopy, Jena, Germany), as previously reported [33,45]. Briefly, in order to visualize Coll I microstructure, Coll I matrices were incubated with $50 \mu \mathrm{M}$ carboxytetramethylrhodamine-succinimidyl ester (TAMRA-SE; Invitrogen, Carlsbad, USA) solution (prepared in PBS) at room temperature for 60 min. Thereafter, Coll I matrices were rinsed 3 times each 5 min with PBS. Coll I matrix microstructure were imaged with a 40× oil immersion objective (NA 1.3; Carl Zeiss Microscopy) in fluorescence mode. Obtained images were 16 bit color-depth with a resolution of $1024 \times 1024$ pixels and with a vertical stack size of 11 images (equivalent to $50 \mu \mathrm{m}$ ). The voxel width in xyz dimension was $0.21 \times 0.21 \times 5 \mu \mathrm{m}$. Image stacks were analyzed using a home-built image analysis tool written in MATLAB (MathWork, Massachusetts, USA). Quantitative analysis of pore size was achieved using an erosion method, and fibril diameter was calculated using 2D autocorrelation [45].

To determine the bulk matrix elasticity of Coll I matrices, colloidal force spectroscopy was used, as previously reported [33]. Briefly, a tip-less, rectangular cantilever was prepared by attaching a glass bead of $50 \mu \mathrm{m}$ in diameter. At least 50 force-distance curves were measured at 3 positions of each Coll I matrix at room temperature with an indentation of 3-7 $\mu \mathrm{m}$. The Young's modulus of the 3D Coll I matrices was determined from the force-distance curves by fitting the Hertz model. Topological and mechanical analyses were performed at least in triplicates.

\subsection{Analysis of HA localization}

The localization of immobilized HA in Coll I matrices was visualized using cLSM (LSM700, Carl Zeiss Microscopy). Modified and non-modified Coll I matrices were incubated with biotin coupled hyaluronic acid binding protein (HABP; dilution 1:1000 in PBS) (AMS Biotechnology, Frankfurt/M., Germany) for $60 \mathrm{~min}$ at room temperature and gentle shaking. After removal of biotin-HABP solution, Coll I matrices were washed 3 times each $5 \mathrm{~min}$, and incubated with streptavidin-conjugated with DyLight $^{\mathrm{TM}} 488$ (dilution 1:1000) (BioLegend, Fell, Germany) for $60 \mathrm{~min}$ at room temperature and gentle shaking. Immobilized HA and Coll I microstructure were visualized using cLSM. Images were gathered with a $40 \times$ oil immersion objective (NA 1.3; Carl Zeiss Microscopy) in fluorescence mode. Obtained images were 16 bit color-depth with a resolution of $1024 \times 1024$ pixels and with a vertical stack size of 
11 images (equivalent to $50 \mu \mathrm{m}$ ). The voxel width in xyz dimension was $0.21 \times 0.21 \times 5 \mu \mathrm{m}$. Localization analysis was performed in triplicates.

\subsection{Quantification of immobilized HA in 3D Coll I matrices}

The quantification of the content of immobilized HA in Coll I matrices was performed by using Alcian blue $8 \mathrm{GX}$ assay. Coll I matrices were digested with papain solution $(0.02 \mathrm{mg} / \mathrm{ml}$ papain from papaya latex (Sigma-Aldrich), $10 \mathrm{mM}$ EDTA (Sigma-Aldrich), $5 \mathrm{mM} \mathrm{L-cysteine} \mathrm{(Sigma-Aldrich)} \mathrm{in} 5 \times$ PBS for $2 \mathrm{~h}$ at $60^{\circ} \mathrm{C}$. Subsequently, digested Coll I solution was incubated with Alcian blue 8GX (SigmaAldrich) for $30 \mathrm{~min}$ at room temperature and gentle shaking. Alcian blue 8GX and HA react to form an insoluble HA-Alcian blue complex. The HA-Alcian blue complex was separated by centrifugation at $15000 \mathrm{~g}$ for $15 \mathrm{~min}$ and $4{ }^{\circ} \mathrm{C}$, followed by washing the sedimented complex 2 times with deionized water. Afterwards, HA-Alcian blue complex formation was reversed by adding $8 \mathrm{M}$ guanidine hydrochloride (dissolved in deionized water) (Sigma-Aldrich). HA dependent dissolved Alcian blue was quantified by absorption measurements at $620 \mathrm{~nm}$ using UV/Vis-spectrophotometer (BioSpectrometer ${ }^{\circledR}$ basic; Eppendorf, Wesseling-Berzdorf, Germany). The absorption value was related to HA amount using a standard curve. HA amounts were analyzed after incubation of HA immobilized Coll I matrices for 1 and 5 days in PBS. All measurements were done at least in triplicates.

To verify HA quantification by Alcian blue 8GX assay, fluorimetry of Atto565-labeled HA was performed after a protocol published recently [46]. Briefly, HA (MW $57 \mathrm{kDa}$ ) derived from ozonolysis of high molecular weight HA (from Streptococcus, MW 1 MDa, Aqua Biochem, Dessau, Germany) was conjugated with Atto565- $\mathrm{NH}_{2}$ (ATTO-TEC, Siegen, Germany) at carboxylic groups along the HA chain. HA immobilization was performed for Coll I matrices of different concentration as described above. Subsequently, matrices were digested using papain (see above) and solutions were analyzed for fluorescence intensity at $\lambda_{\mathrm{ex}}=535 \mathrm{~nm}$ and $\lambda_{\mathrm{em}}=590 \mathrm{~nm}$ in 96-microplate reader (Infinite 200 PRO, Tecan, Männedorf, Switzerland). The fluorescence intensity was related to HA amount using a standard curve. HA amounts were analyzed after 1 day of incubation in PBS. All measurements were done at least in triplicates.

\subsection{Cell culture and quantification of cell number}

BRO cell line [47] expressing high levels of CD44 (transcript variant 4, NM_001001391, [48]) was used for the experiments. The cells were kept in RPMI-1640 supplemented with $10 \%$ fetal calf serum and $1 \%$ ZellShield (Biochrom, Berlin, Germany) at $37{ }^{\circ} \mathrm{C}, 5 \% \mathrm{CO}_{2}$ and $95 \%$ humidity.

CD44 knockdown cell (BRO P10 or BRO CD44- cells) was achieved by CRISPR-CAS9 (D10A) mediated genome editing. Briefly, BRO cells were transfected with bi-cistronic plasmids expressing simultaneously sgRNA docking to exon 2 common to all CD44 transcript variants and CAS9 (DNA2.0, San Diego, CA, USA; for plasmid map see Figure S1). Clones with a complete loss of CD44 protein expression were obtained after limited dilution assay and by comprehensive analysis including flow cytometry (CD44-PE (clone DB105, MiltenyiBiotech, Bergisch-Gladbach, Germany) and Western blot analysis with anti-CD44-antibodies (clone SFF304 (ebioscience, Frankfurt, Germany), see Figure S2.

$1 \times 10^{4}$ cells were cultivated on non-modified and modified Coll I matrices in RPMI-1640 medium supplemented with $10 \%$ fetal calf serum and $1 \%$ ZellShield (anti-biotic) at $37{ }^{\circ} \mathrm{C}, 5 \% \mathrm{CO}_{2}$ and $95 \%$ humidity for 4 days (all from Biochrom).

To determine cell proliferation using commercial WST-1 assay (Cayman, Michigan, USA), matrices were washed 3 times with Hank's buffered salt solution with calcium and magnesium (HBSS) 
(Biochrom) and $300 \mu \mathrm{L}$ of the WST-1 reaction mixture (1:10 dilution in RPMI-1640 cell culture medium without phenol red, Biochrom, Germany) were incubated for $60 \mathrm{~min}$ at standard cell culture condition. Subsequently, supernatant was collected and the absorption measurement at $450 \mathrm{~nm}$ was performed using 96-microplate reader. The relative amount of vital cells was normalized to non-modified Coll I matrices. Experiments were performed at least 6 times.

\subsection{Flow cytometry analysis of CD44 expression}

Flow cytometry analysis of CD44 expression was done prior to each cell experiment. Cells were detached from cell culture flasks using $10 \mathrm{mM}$ ethylenediaminetetraacetic acid (EDTA) (SigmaAldrich). Cells were centrifuged at $1500 \mathrm{rpm}$ for $5 \mathrm{~min}$ and resuspended in PBS. Cells were fixed with 4\% paraformaldehyde (PFA; Roth, Germany) for $10 \mathrm{~min}$ and were centrifuged at $1500 \mathrm{rpm}$ for $5 \mathrm{~min}$. The cell pellet was resuspended in PBS and stained with anti-human/mouse CD44 IM7 APC antibody (dilution 1:100 in PBS) (Biolegend) for 15 min (gentle shaking). Thereafter, stained cells were washed in PBS and centrifuged at $1500 \mathrm{rpm}$ for $5 \mathrm{~min} .1 \times 10^{4}$ cells were analyzed using a flow cytometer FC 500 (Beckman Coulter, Krefeld, Germany).

\subsection{Quantitative analysis of cell invasion}

To investigate the invasion behavior and morphology of cells after 4 days of cell culture, cells were fixed with $4 \%$ paraformaldehyde for 15 minutes. Subsequently, cells were stained with DAPI (dilution 1:10.000 in PBS) and Alexa Fluor ${ }^{\circledR} 488$ Phalloidin (dilution 1:100 in PBS) (both Invitrogen) for 60 min at room temperature. Quantitative analysis of cell invasion, e.g. invasion depth and percent of invasive cells, was analyzed using a home-built MATLAB script, as previously reported [33]. At least 3 positions of each sample were gathered using epi-fluorescence microscopy equipped with z-scan stage (AxioObserver.Z1; Carl Zeiss Microscopy). Image stacks were recorded with a 10×, NA 0.45 objective (Carl Zeiss Microscopy) in fluorescence mode (DAPI fluorescent signal) at $5 \mu \mathrm{m} \mathrm{z}$ distance (overall zdepth was $400 \mu \mathrm{m})$. The 8-bit images were $1388 \times 1040$ pixels in resolution (xy dimension). Experiments were performed at least in triplicate.

\subsection{Quantification of CD44-HA adhesive interaction using soft colloidal probes}

The interaction between CD44 and HA, both LMW-HA and HMW-HA, was studied using soft colloidal probes (SCP) techniques, as previous reported [49]. Briefly, soft colloidal probes were synthesized by UV induced photo-polymerization of $6.3 \mu \mathrm{M}$ PEG-diacrylamide (MW $=8000 \mathrm{Da}$; Sigma-Aldrich) followed by grafting with crotonic acid (Sigma-Aldrich) [50,51]. Thereafter, SCP was functionalized with HA using a two-step reaction. Firstly, $20 \mathrm{mM}$ EDC (Sigma-Aldrich) was prepared in 0.1 M MES buffer (pH 5) (Sigma-Aldrich) supplemented with $1 \mathrm{mg} / \mathrm{ml}$ poly-L-lysine (PLL; 30-70 kDa; SigmaAldrich). SCPs were incubated with the prepared EDC solution for $30 \mathrm{~min}$ at room temperature and gentle shaking. Subsequently, SCPs were washed 3 times with $0.1 \mathrm{M}$ MES buffer ( $\mathrm{pH} 5$ ) and centrifuged at $5000 \mathrm{rpm}$ for $5 \mathrm{~min}$ at room temperature. The second solution composed of $20 \mathrm{mM}$ EDC and $1 \mathrm{mg} / \mathrm{ml}$ HA in 0.1 M MES buffer ( $\mathrm{pH} 5$ ) was prepared. The SCPs were incubated for $3 \mathrm{~h}$ at room temperature and gentle shaking, resulting in a covalent immobilization of HA to the SCPs. The functionalized SCPs with HA (HA-SCP) were washed 2 times with PBS and stored in PBS with $0.1 \mathrm{wt} \%$ sodium azide (Sigma-Aldrich) prior to use.

To perform the experiment, HA-SCP was glued to a non-coated cantilever (CSC12 nominal spring constant $0.03 \mathrm{~N} / \mathrm{m}$; NanoAndMore GmbH, Wetzlar, Germany) using an epoxy glue (Epoxy Resin 
Adhesives (2-Component); UHU GmbH, Bühl, Germany). The experimental setup is depicted in Figure 6A. For the measurement, the cantilever was positioned above a cell and several force curves were recorded with a maximum contact force of $3 \mathrm{nN}$ and contact times between 0 and $30 \mathrm{~s}$. At least 40 cells of both CD44- and CD44+ BRO melanoma cells were analyzed.

Cell stiffness was derived from colloidal force spectroscopy measurements using force-deformation curves of both CD44+ and CD44- cells with cantilevers modified with colloidal glass beads (30-50 $\mu \mathrm{m}$ in diameter; PolySciences Inc, Warrington, USA). Maximum indentation force was set to $5 \mathrm{nN}$ and the indentation depth was approximately 1-2 $\mu \mathrm{m}$. The elastic moduli of at least 40 cells were analyzed via the Hertz contact model (Figure S6).

\subsection{Statistical analysis}

Data are presented as means \pm standard deviation. Significant analysis was assessed by one-way ANOVA test and accepted as statistically significant at $\mathrm{p}<0.05$ using OriginPro 8 (OriginLab, USA). If not otherwise stated, experiments were performed at least triplicates.

\section{Results and discussion}

In order to investigate the influence of HA molecular weight and presentation mode in solid tumor microenvironment, HA with a molecular weight of 30-50 kDa (LMW-HA) and of 500-750 kDa (HMWHA) was covalently immobilized to reconstituted Coll I matrices. Immobilized amount of HA and its impact on topological and mechanical parameters of the matrices were evaluated. To elucidate the interaction between CD44 and HA, BRO melanoma cell lines with and without CD44 expression were studied regarding proliferation, invasion and adhesion.

\subsection{Functionalization and characterization of HA immobilized Coll I matrices}

Coll I matrices were reconstituted at Coll I concentration of 1.5, 2.0 and $2.5 \mathrm{mg} / \mathrm{ml}$, and subsequently modified with LMW-HA (30-50 kDa) or HMW-HA (500-750 kDa). A previous report demonstrated that functionalization of Coll I with GAG using post-modification and crosslinking by EDC provides a stable GAG immobilization in comparison to approaches using mixtures of GAG and Coll I during fibrillation [42]. Furthermore, this approach avoids variation in fibril micro- and nanostructure due to the GAG presence [52]. In Figure 1 the microstructure of non-modified, crosslinked Coll I and HAmodified networks is depicted. As expected, the images show that an increase of Coll I concentration led to a higher fibril density. Crosslinked Coll I matrices with EDC and modification with HA of both molecular weights appear with a similar microstructure at corresponding concentration. Quantitative analysis of topological parameters revealed the pore size to decrease with increasing Coll I concentration, with $6.6 \pm 0.7,4.7 \pm 0.6$ and $3.1 \pm 0.6 \mu \mathrm{m}$ for $1.5,2.0$ and $2.5 \mathrm{mg} / \mathrm{ml}$ Coll I concentration, respectively (Figure 2A). EDC crosslinking and HA modification did not affect the pore size dependence. These observations are in agreement with previous reports $[33,45]$. The fibril diameter parameter of the autocorrelation analysis was approximately $700 \mathrm{~nm}$ for all matrices. The results suggest that post-modification with EDC crosslinker and covalent immobilization of HA did not alter Coll I matrix microstructure, confirming findings previously reported for various GAG [42].

For the investigation of the HA localization in Coll I matrices, reconstituted matrices were stained with HABP-biotin/streptavidin DyLight488 and TAMRA-SE to visualize immobilized HA and Coll I fibrils, respectively. Representative images of HA immobilized Coll I matrices are shown in 
Figure 1, suggesting uniform distribution of HA in 3D Coll I matrices. The image indicate that HA is localized on Coll I fibrils in agreement with our previous work [42].

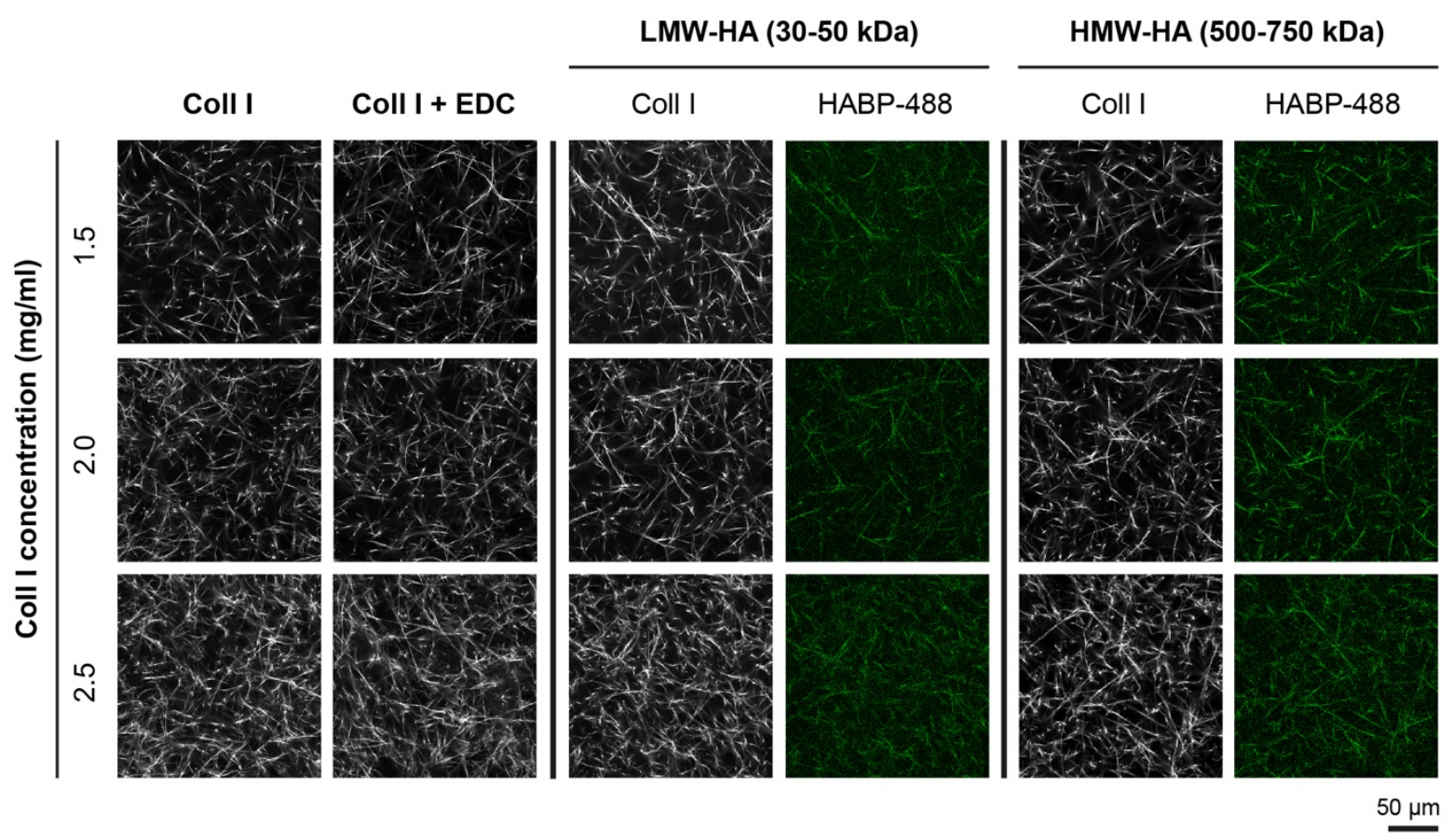

Figure 1. Representative images of microstructure of non-modified and EDC and HA modified Coll I matrices. Coll I matrices were reconstituted at concentration of 1.5, 2.0 and $2.5 \mathrm{mg} / \mathrm{ml}$ at $\mathrm{pH} 7.5$, and modified with EDC crosslinker and HA of different molecular weight, namely LMW-HA (30-50 kDA) and HMW-HA (500-750 kDa). To image matrix microstructure, Coll I was stained with TAMRA-SE. Both LMW-HA and HMW-HA were stained with hyaluronic acid binding protein (HABP) conjugated with biotin and subsequent staining with a Streptavidin-DyLight $488^{\mathrm{TM}}$. Experiments were performed at least in three independent experiments.

Beside topological parameters and HA localization, bulk matrix elasticity was analyzed using colloidal probe force spectroscopy. As shown in Figure 2B, Young's modulus is increased by increasing Coll I concentration, namely $50 \pm 16,80 \pm 30$ and $150 \pm 50 \mathrm{~Pa}$ for $1.5,2.0$ and $2.5 \mathrm{mg} / \mathrm{ml}$ Coll I concentration, respectively. As reported previously [32,33,45,53], the Young's modulus of Coll I matrices is proportional to an increasing Coll I concentration as a result of the decreasing fibril density and pore size. The bulk matrix stiffness of Coll I matrices can be increased using crosslinkers such as EDC [42,54] and glutaraldehyde [53]. In this study, EDC crosslinker was used because its properties as a zero-length cross-linker does not result in any alteration of Coll I microstructure [42]. By crosslinking with $20 \mathrm{mM}$ EDC, stiffness of reconstituted Coll I matrices increased to $75 \pm 30,160 \pm 80$ and $220 \pm$ $100 \mathrm{~Pa}$ for $1.5,2.0$ and $2.5 \mathrm{mg} / \mathrm{ml}$ Coll I concentration, respectively. After immobilizing HA via EDC, an additional increase of matrix stiffness was observed (Figure 2B). This effect becomes less significant for high Coll I concentrations ( 2.0 and $2.5 \mathrm{mg} / \mathrm{ml})$. Furthermore, no difference in matrix stiffness was observed depending on incorporation of LMW-HA or HMW-HA (Figure 2B).

In summary, microstructure of Coll I matrices can be adjusted by Coll I concentration, but is unaltered by crosslinking and HA modification. However, bulk matrix stiffness increases not only with increasing fibril density (and corresponding smaller pore size), but is increased by crosslinking. A further small increase in matrix stiffness is observed by HA modification. The latter effect was also reported in other studies $[42,55]$ and was attributed to the high water binding capacity of HA [56]. Either 
the strong swelling of bound HA molecules increases the stiffness of Coll I fibrils or local osmotic effects of water binding in HA molecules impact intrafibrillar Coll I structure and mechanics as recently shown for rat tendons at varied humidity [57]. Although a minor effect is observed in our system, both mechanisms could contribute to a slight increase of Young`s modulus of Coll I with immobilized HA.

A

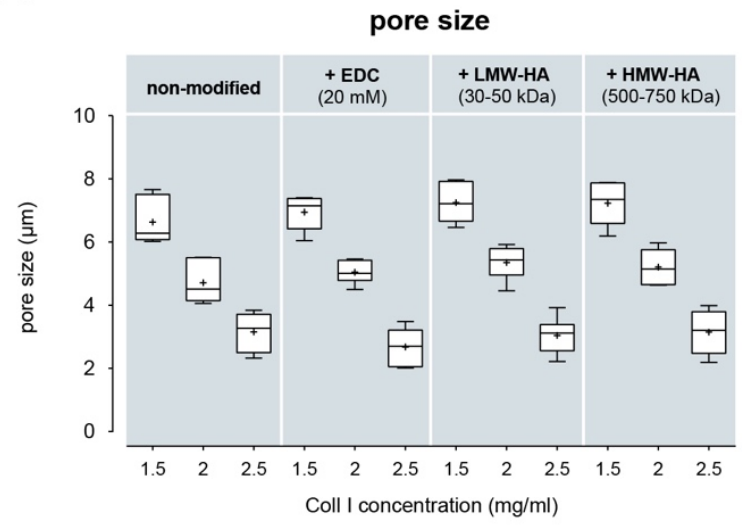

B

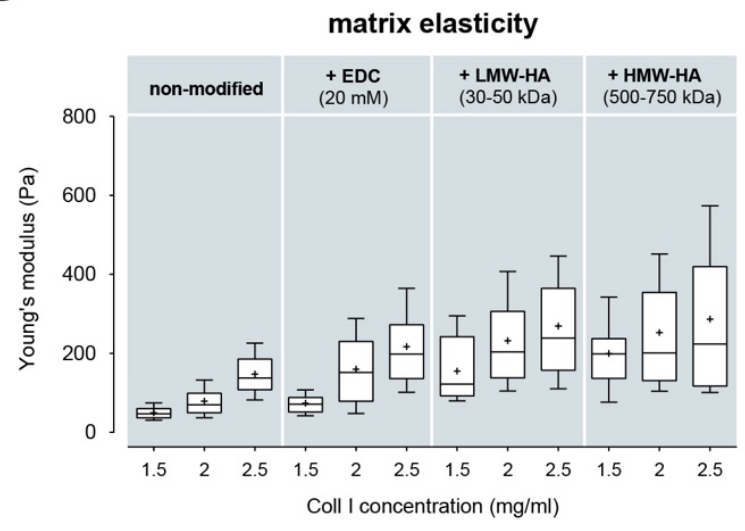

Figure 2. Quantitative analysis of pore size and bulk matrix elasticity of non-modified and EDC and HA modified Coll I matrices. (A) pore size and (B) matrix elasticity analysis of Coll I matrices reconstituted at Coll I concentration of $1.5,2.0$ and $2.5 \mathrm{mg} / \mathrm{ml}$ at $\mathrm{pH} 7.5$. Matrix post-modification was performed with EDC crosslinker and HA of different molecular weight, namely LMW-HA (30-50 kDa) and HMW-HA (50-750 kDa). Image-based pore size analysis was performed in three independent experiments with $n=3$ positions for each Coll I matrix. For matrix elasticity analysis using soft colloidal probe technique, about 50 force-distance curves were measured at 3 positions of each Coll I matrix within 3 independent experiments. Experiments were performed at least in three independent replicates. Data are shown as box plots: $+\ldots$ mean, box...median with $10^{\text {th }}$ and $90^{\text {th }}$ percentiles, error bars...minimum and maximum values.

\subsection{Stability and amount of HA in 3D Coll I matrices}

Prior to cell experiments it is of major importance to ensure a constant availability of HA. Quantitative analysis of immobilized HA amount was performed using Alcian blue assay. Alcian blue is a cationic dye binding to acidic polysaccharides through a complex formation [58,59]. Furthermore, we used our established fluorimetric protocol for fluorescent conjugated HA to verify the quantitative analysis of the Acian blue assay (Figure S3).

By comparing amount of immobilized HA at day 1 and day 5 after matrix functionalization, ranging between 2 and $6 \mu \mathrm{g}$ HA per Coll I matrix, HA could be verified to be stably immobilized on Coll I matrices as expected from our previous studies [42] (Figure 3A). Only a low, non-significant decrease of HA amount was observed. Furthermore, HA amount was found to depend on concentration of fibrillized Coll I and on molecular weight of HA. An increasing Coll I concentration led to an increase of immobilized HA for both LMW-HA and HMW-HA. Normalizing the absolute HA amount to the amount of fibrillized Coll I indicated 2 effects: (I) HA amount is directly related to amount of Coll I leading to a constant HA/Coll I ratio and (II) that this ratio is MW dependent with approx. $0.05 \mu \mathrm{g}$ HA per $\mu \mathrm{g}$ Coll I for LMW-HA and $0.1 \mu \mathrm{g}$ HA per $\mu \mathrm{g}$ Coll I for HMW-HA (Figure 3B). Both findings point to a dense immobilization of HA on the surface of Coll I fibrils in the matrices, as discussed in our previous study [42]. With increasing Coll I concentration a high number of fibrils (corresponding fibril surface) is available for HA immobilization, which compares well to the decreasing pore size 
(Figure 2A). Furthermore, the different HA/Coll I ratios compare very well with the MW of the used HA. For our immobilization protocol in aqueous state and the dense packing of HA molecules on Coll I fibrils (see above), the amount of immobilized HA should be proportional to the hydrodynamic radius of HA molecules. The hydrodynamic radius of a compact polyelectrolyte at high ionic strength of solution should approximately scale with MW by an exponent of 1/3 [60]. The ratio of hydrodynamic radii of LMW-HA $(\approx 40 \mathrm{kDa})$ and HMW-HA $(\approx 625 \mathrm{kDa})$ estimated with the above assumption calculates to 0.4 . This ratio roughly compares to the ratio of normalized HA amounts per Coll I for LMW-HA and HMW-HA being 0.5 supporting a dense packing of HA on Coll I fibrils.

In summary, the analysis showed that HA is stable immobilized and densely packed on fibrillar Coll I matrices.

A

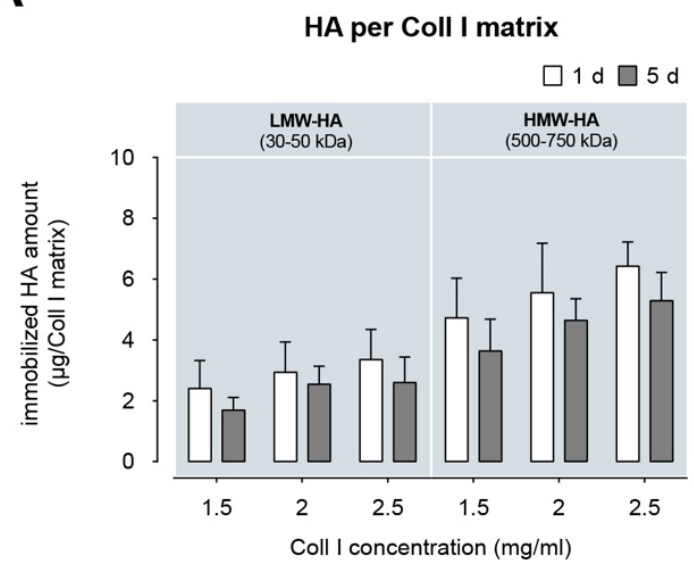

B

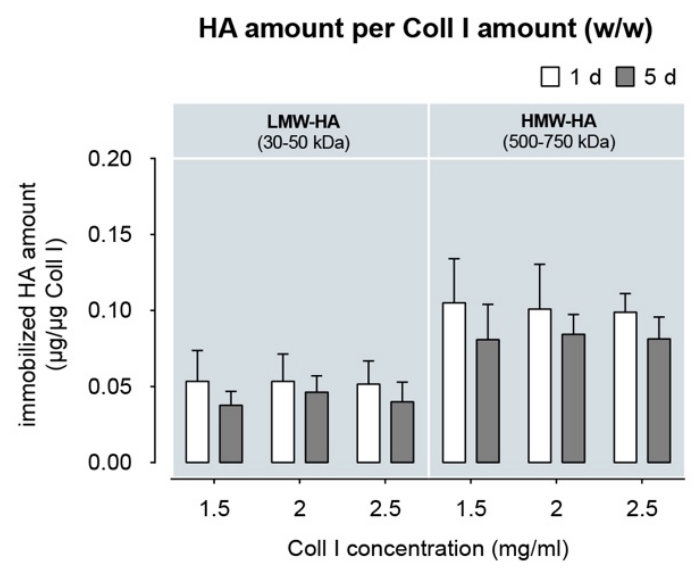

Figure 3. Quantification of immobilized HA in 3D Coll I matrices. For quantitative analysis of immobilized HA amount in 3D Coll I matrices, matrices were digested with papain solution and the concentration of HA was analyzed using quantitative Alcian blue assay by absorption measurement at $621 \mathrm{~nm}$. Concentration of immobilized HA was analyzed at day 1 and day 5 after network modification. (A) The immobilized amount of HA per Coll I matrix and (B) HA amount per Coll I amount (w/w) ( $\mu \mathrm{g} / \mu \mathrm{g}$ Coll I) are shown for Coll I concentrations of 1.5, 2.0 and $2.5 \mathrm{mg} / \mathrm{ml}$. Data are shown as mean. Error bars represent standard deviation of mean. Analysis was performed in 4 independent experiments.

\subsection{Cell experiments}

Interactions between cells and extracellular HA are predominantly triggered by CD44, a multifunctional cell surface receptor implicated in a huge variety of intracellular signaling pathways. In order to address the interaction between tumor cells and their HA-rich microenvironment, BRO melanoma cell lines with (CD44+) and without CD44 (CD44-) receptor were applied in the cell studies. From our set of Coll I matrices we chose matrices with $2.5 \mathrm{mg} / \mathrm{ml}$ Coll I, because no considerable differences in matrix stiffness were observed between EDC crosslinked and HA modified (via EDC chemistry) matrices. This allowed us to focus on the impact of the HA presentation scheme for CD44 interaction.

Prior to each cell experiments, BRO melanoma cells were analyzed regarding their expression of CD44 using flow cytometry (Figure S2 A). 


\section{Unaffected cell morphology by HA MW and availability form}

To assess the morphological appearance of CD44+ and CD44- BRO melanoma cells on modified and non-modified Coll I matrices, cells were stained with DAPI (nucleus) and Phalloidin conjugated with Alexa Fluor ${ }^{\circledR} 488$ (actin cytoskeleton), and analyzed using cLSM after 4 days of culture (Figure 4A). No remarkable difference in morphological appearance could be observed between CD44+ and CD44BRO melanoma cells, both exhibit an epithelial, triangular or elongated ovoidal phenotype with a prominent nucleus and clearly visible nucleoli in all matrices. The results suggest that HA MW as well as HA availability form (soluble or immobilized) did not markedly modulate changes of cell morphology of both cell types.

A

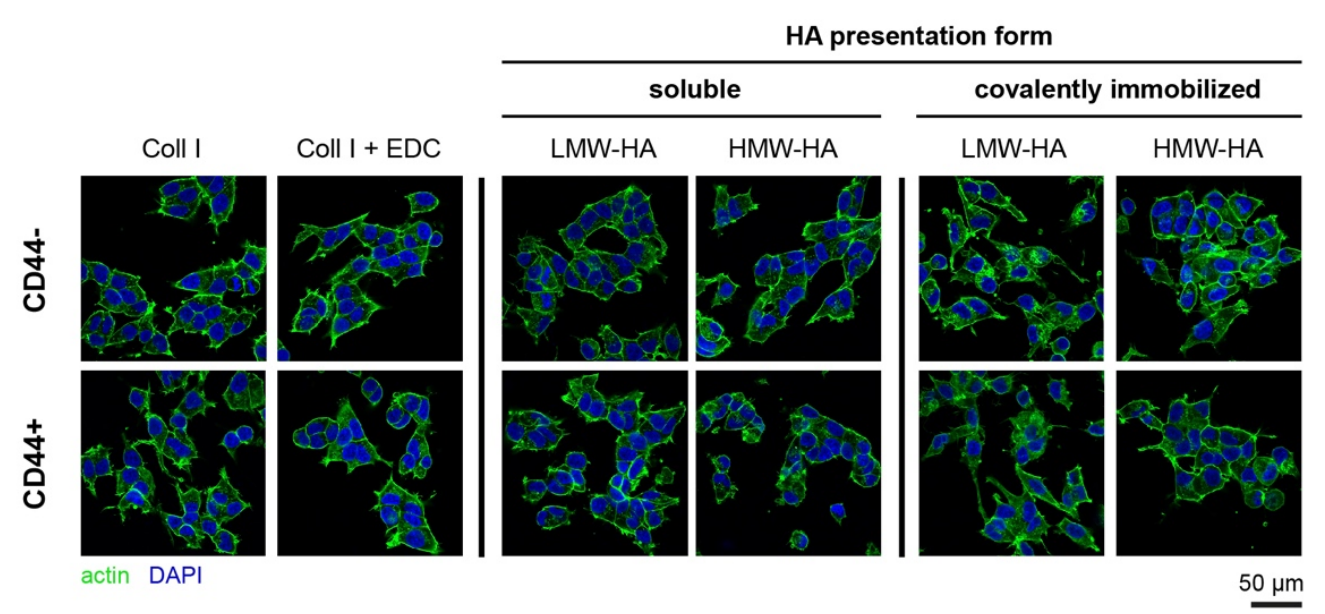

B

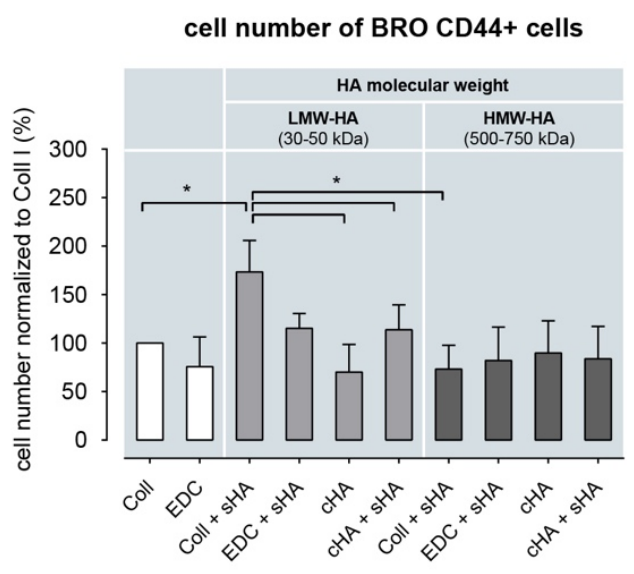

C

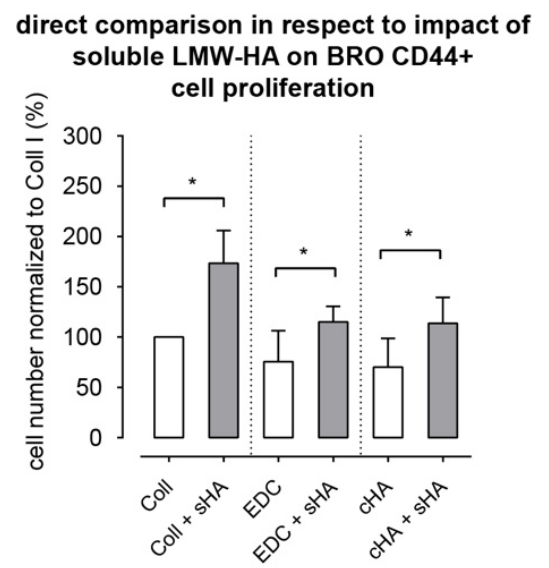

Figure 4. Morphology and proliferation analysis of BRO melanoma cells cultivated on 3D Coll I matrices with and without post-modification with EDC cross-linker and HA. BRO melanoma cells with and without CD44 expression were cultivated for 4 days on 3D Coll I matrices reconstituted at Coll I concentration of 2.5 $\mathrm{mg} / \mathrm{ml}$ at $\mathrm{pH}$ 7.5. Coll I matrices were either crosslinked with EDC (Coll-EDC) or post-modified with LMW-HA or HMW-HA (cHA: covalently immobilized HA) or optionally supplemented with soluble HA (sHA) at a concentration of $5 \mu \mathrm{g} / \mathrm{ml}$. (A) Representative images of BRO melanoma cells on modified and non-modified matrices in the presence of HA in soluble and immobilized forms. Cells were stained with DAPI and Alexa Fluor® Phalloidin 488 to visualize cell nucleus and actin cytoskeleton. (B) Cell proliferation of BRO melanoma cells with CD44 expression was measured using WST-1. (C) Data from Figure 4B was rearranged to demonstrate the impact of soluble LMW-HA in modified and non-modified matrices. Data were normalized to non-modified Coll I matrices (Coll). Data are shown as mean. Error bars represent standard deviation of mean. * represents statistical significance with $\mathrm{p} \leq 0.05$. Experiments were performed at least in 4 independent experiments. 


\section{Soluble LMW-HA enhanced proliferative capacity}

In order to evaluate the impact of HA size and presentation form on proliferation via CD44 interaction, cell proliferation of both BRO melanoma cell lines was analyzed after a cultivation period of 4 days using WST-1 assay. In Figure 4B, relative cell number normalized to non-modified Coll I matrices is depicted for CD44+ BRO melanoma cells. The proliferation of CD44- BRO melanoma cells was not influenced by EDC crosslinking and the presence of HA, independent of MW and presentation form (Figure S4).

In contrast, the proliferation of CD44+ cells was regulated by the presence of LMW-HA, but not HMWHA (Figure 4B). The presence of LMW-HA led to distinct effects in dependence on its presentation form. In the presence of soluble LMW-HA (Figure 4C), cell number after 4 days was markedly increased by approximately $75 \%$ compared to non-modified Coll I. It is important to note, that the presence of soluble LMW-HA in combination with EDC crosslinking or LMW-HA immobilization (which also includes EDC crosslinking) increased the relative cell number by approximately $61 \%$ compared to crosslinked matrices without soluble LWM-HA. Immobilized LMW-HA was not found to be active in this context. On top of the impact to soluble LMW-HA we found cell proliferation to be slightly decreased by $25 \%$ due to crosslinking (either pure EDC or in the context of HA immobilization) in comparison to non-modified Coll I.

The results indicate that the proliferation of BRO melanoma cells is regulated via CD44 in dependence on presence of soluble LMW-HA as well as EDC crosslinking. In the presence of LMW-HA in a covalently attached form as well as the presence of HMW-HA in any form did not affect the CD44 dependent proliferation of BRO melanoma cells. It is followed that the CD44 dependent proliferative activity of LMW-HA depends on its presence in a soluble form, because it might be the prerequisite for internalization by CD44 and HYAL2 and subsequent intracellular signaling [28,61-63]. HMW-HA seems to be too large for this process, while covalent immobilization inhibits CD44 dependent internalization as well. An alternative interpretation could be based on differences in the mobility of the HA ligands. CD44 reorganization in the cell membrane after HA binding is known to affect its intracellular signaling [64]. Such a process would be also dependent on the presentation form of HA, with soluble LMW-HA being mobile, but covalently bound LMW-HA and HMW-HA being not or

weakly mobile. Furthermore, our findings suggest an additive effect of matrix stiffness on the CD44 dependent proliferation of BRO melanoma cells as proliferation is decreased on stiffer (crosslinked) matrix. This reduction of proliferation of CD44+ cells in EDC crosslinked matrices (compared to nonmodified matrices) might be caused by the interplay of CD44 with the mechanosensing via integrin receptors [65]. However, the activation of proliferation via soluble LMW-HA acts on top of this process.

\section{Immobilized LMW-HA triggered invasiveness}

We further investigated the role of CD44 in regulation of cell invasion regarding the number of invasive cells and their invasion depth. The quantification of invasive behavior was analyzed by DAPI staining using epi-fluorescence microscopy and a home-built MATLAB script counting detected cell numbers in image stacks with vertical size of $400 \mu \mathrm{m}$ (Figure 5A and 5B). In all experiments, $50 \%$ of both CD44+ and CD44- cells migrated deeper than $20 \mu \mathrm{m}$ into the Coll I matrix independent of the Coll I matrix modification (Figure S5). Furthermore, the maximum invasion distance of CD44- cells invaded was independent of HA MW and presentation form with approx. $30 \mu \mathrm{m}$ (Figure 5C). A change of maximum invasive distance could be solely observed for CD44+ cells (Figure 5D). CD44+ cells cultivated on nonmodified Coll I matrices and EDC crosslinked matrices exhibited an invasion distance of approx. 50 $\mu \mathrm{m}$. In the presence of both, soluble and immobilized HMW-HA, maximum invasion distance was slightly decreased compared to cells cultivated on non-modified and EDC crosslinked matrices. However, immobilization of LMW-HA led to a remarkable increase of maximum invasion distance 
being approx. $110 \mu \mathrm{m}$. In contrast, presence of soluble LMW-HA did not alter the maximum invasion distance compared to non-modified matrices. Furthermore, the increased invasion on covalently immobilized LMW-HA is almost complete blocked with an additional presence of soluble LMW-HA with only a minor, statistically non-significant increase of maximum invasion distance compared to nonmodified matrices. A similar non-significant increase of maximum invasion distance was observed also in the presence of soluble LWM-HA on EDC crosslinked matrices.

A

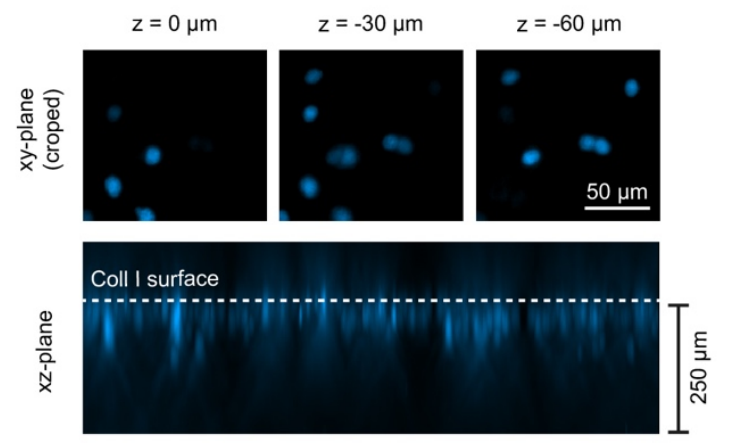

C

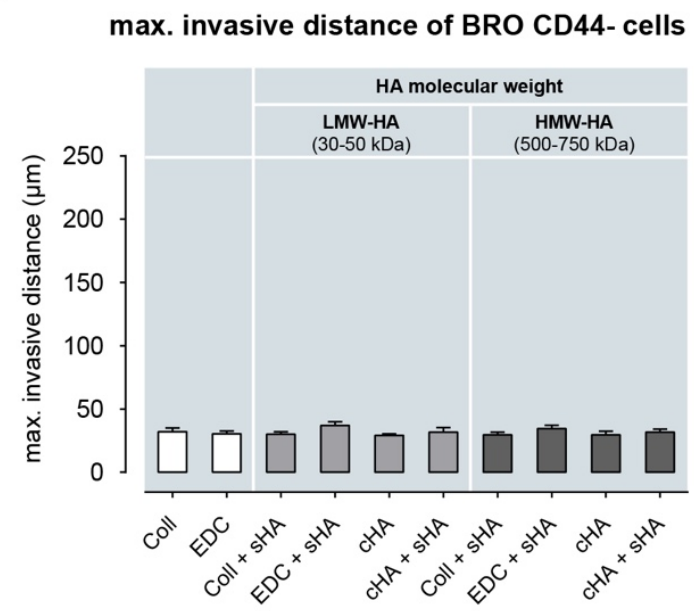

B

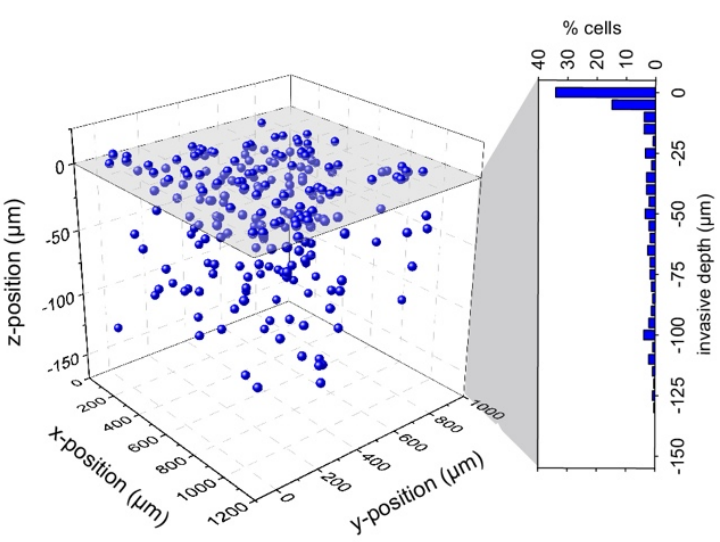

D

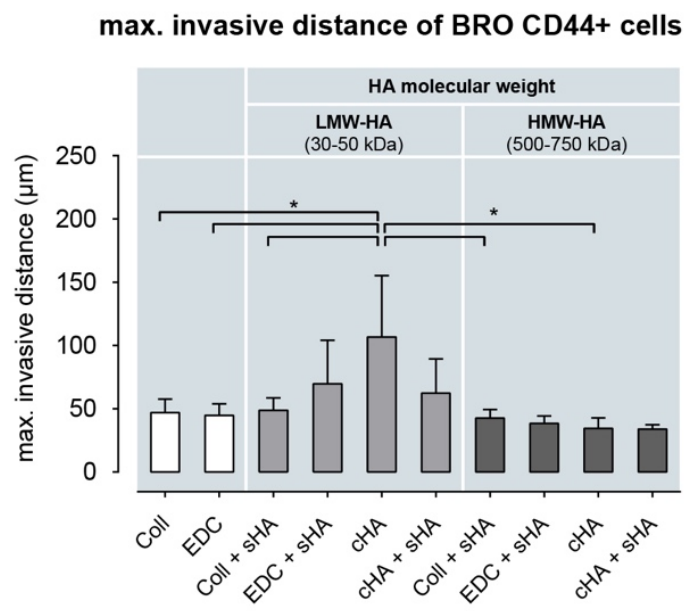

Figure 5. Invasion analysis of BRO melanoma cells cultivated on 3D Coll I matrices with and without post-modification with EDC crosslinker and HA. Coll I matrices were either crosslinked with EDC (CollEDC) or post-modified with LMW-HA or HMW-HA (cHA: covalently immobilized HA) and optionally supplemented with soluble HA (sHA) at concentration of $5 \mu \mathrm{g} / \mathrm{ml}$. (A) and (B) show the principle of invasion analysis for the example of CD44+ BRO melanoma cells in Coll I matrices with immobilized LMW-HA. Cells located $>20 \mu \mathrm{m}$ below the Coll I matrix surface were counted as invaded cells. Maximum invasion distance of CD44- (C) and CD44+ (D) BRO melanoma cells was defined as the mean invasion distance of $10 \%$ of all cells with the highest invasion distance. Data are shown as mean. Error bars represent standard deviation of mean. * represents statistical significance with $p \leq 0.05$. Experiments were performed at least in 4 independent experiments.

These findings suggest that CD44-HA interaction may enhance BRO melanoma cell invasion in presence of covalently immobilized LWM-HA. Presence of soluble LMW-HA inhibits this behavior, which points to a direct, adhesive interaction of LMW-HA to CD44. In contrast, presence of HMW-HA had no specific effect in dependence on presentation form on BRO melanoma cell invasion. In minor, non-significant decrease for covalently immobilized HMW-HA compared to Coll I matrices might 
originate from a non-specific disturbance of the receptor-ligand interaction of other cell surface receptors, e.g. integrins, which are important in cell-matrix interaction and cell migration. These results are in line with a previous report, which stated immobilized HA, but not soluble, to enhance migration of breast tumor cells [66].

\section{Interaction between CD44 and LMW-HA is stronger than HMW-HA}

To support our hypothesis of a direct adhesive interaction of CD44 with LMW-HA in the discussions above, AFM force-distance measurements using the SCP technique was implemented to quantify CD44HA interaction on living cells. The schematic methodology of SCP technique was previously published [49] and is illustrated in Figure 6A. The SCP technique has the advantage to mimic cell-matrix interactions quite closely via the soft hydrogel character of the colloidal probe, the flexible attachment of ligands (or receptors) on the well-hydrated probe and the option to form multivalent binding sites due to the micrometer sized probe. Furthermore, the low stiffness of the probe in the range of a typical cell stiffness (see also Figure S6) allows to directly quantify pull-off forces as a measure of receptor-ligand interactions, for details see [49]. As shown in Figure 6B from typical force-distance curves between CD44+ and CD44- BRO melanoma cells and LMW-HA modified SCPs at 30s contact time distinct difference in cell-SCP interaction can be determined. During retraction the distinct and large pull-off force in the presence of CD44 receptor indicates a strong interaction. Importantly, pull-off forces between LMW-HA and CD44+ cells were much higher than any other sample, clearly pointing to a highly specific and adhesive interaction between LMW-HA and CD44 (e.g. $7.6 \pm 2.4 \mathrm{nN}$ at $30 \mathrm{~s}$ ). LMWHA interaction to CD44- cells as well as HMW-HA interaction to CD44+ were much lower $(1.5 \pm$ $1.5 \mathrm{nN}, 2.4 \pm 0.7 \mathrm{nN}$ at $30 \mathrm{~s}$ for LMW-HA/CD44- and HMW/CD44+, respectively). For HWM-HA interaction to CD44- cells pull-off forces in the range of non-specific interactions of non-coated SCP $(0.2 \pm 0.1 \mathrm{nN}$ at $30 \mathrm{~s}$, see Figure S7) were observed.

A

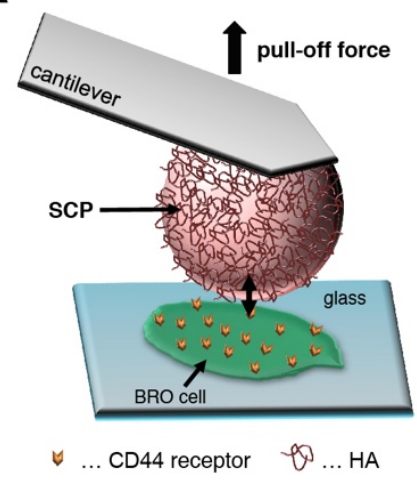

B

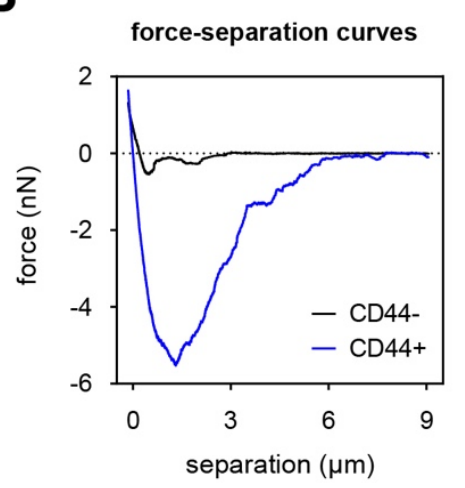

C

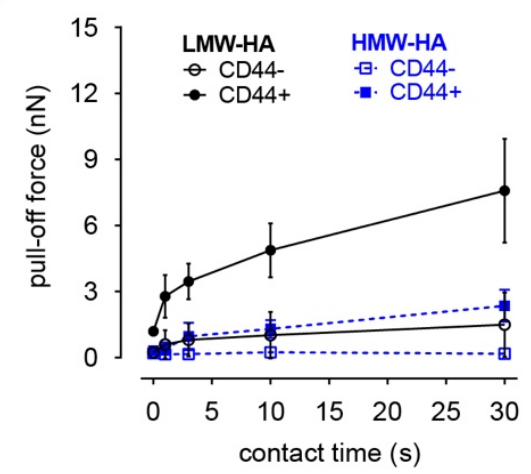

Figure 6. Quantification of CD44-HA interaction using soft colloidal probe technique. (A) Schematic illustration of the soft colloidal probe approach as a tool to study HA-CD44 interaction on single living cells. (B) Typical force-deformation curves of LMW-HA coated SCPs on CD44+ (blue) and CD44- (black) BRO melanoma cells at contact time of $30 \mathrm{~s}$. (C) Measurement of pull-off forces of LMW-HA and HMW-HA on BRO melanoma cells with and without CD44 expression at contact times of $0,1,3,10$ and $30 \mathrm{~s}$. Data are shown as mean from at least 40 cells out of 3 independent experiments. Error bars represents standard deviation of mean.

By investigating various dwell times for CD44-HA interaction between 0 and $30 \mathrm{~s}$, we observed a fast onset of CD44-HA engagement during the first $3 \mathrm{~s}$ followed by a slower constant increase. The latter effect can be attributed to the reorganization of CD44 receptor in the cell membrane and cytoskeletal 
components in the cell. Especially, the hypothesis of a non-specific intracellular reorganization is supported by the similar time dependence for all samples, independent on the specific force magnitude.

We herein cannot reveal the underlying mechanism between highly adhesive interaction of LMW-HA and CD44 and the very weak interaction of HMW-HA. One might speculate on a difference in the entropical contribution of the differently sized polymer chains of HA molecules to the physicochemical interaction with the CD44 receptor, while other descriptive models on the modulated interaction of CD44 with different forms of MW of HA via modulation of CD44 binding stability [67], CD44 clustering [68] or co-receptors are available as well [26,28]. However, most importantly we can quantitatively show that LMW-HA can drive a specific and highly adhesive interaction to CD44 receptors on living cells, which cannot be observed for HMW-HA or CD44- BRO melanoma cells.

\section{General Discussion}

Our results of proliferative and invasive behavior of BRO melanoma cells in HA-modified Coll I matrices led to the conclusion, that CD44 mediated cellular effects are dependent on HA MW and its presentation form, being soluble or covalently immobilized. In general, LWM-HA is suggested to exhibit a strong direct interaction with CD44, while small effects of HMW-HA are subtler and probably indirect. Moreover, in vivo the organization and structural functionalization of HA strains by proteins like TSG6, pentraxin 3 and other associated proteoglycans may determine the functionality of HMWHA as a part of complex GAG-protein structures in activated tissues like wounds or tumor stroma [69]. The HMW-HA confers signals of homeostasis in resting tissue and thus seems to be less stimulating than smaller, degraded HA-molecules probably transporting stimulating danger signals.

Soluble LMW-HA contributed to an enhanced proliferation, which was suggested to result from CD44 mediated internalization and downstream signal activation, as immobilized LMW-HA and HMW-HA could not act in this manner. Similarly, a strong adhesive interaction of CD44 and LMWHA was found in the SCP measurements and only immobilized LMW-HA contributed to an enhanced invasion of CD44+ BRO melanoma cells. This interpretation of our results fits to reports arguing direct binding of LMW-HA to CD44 activates downstream signaling cascades including the Rho GTPase, the Ras-MAPK and the PI3K/AKT pathways [26,70-72]. Cell survival, growth and invasion were therefore found to be promoted. Similar effects were obtained by the interaction of CD44 with other cell surface receptors, e.g. the oncogenes c-Met and ErbB $[26,73]$. On the other side, the presence of HMW-HA and a high cell density led to the displacement of ERM proteins by hypophosphorylated Merlin and the inhibition of the Ras-activated cell growth [74], supporting the more indirect function of HMW-HA.

Our findings should be also discussed in the context of the multiple functions of CD44 at different stages of not only tumor initiation and progression [28]. Although previous studies postulated a significant overexpression of activated CD44 of different transcript variants in solid tumors $[75,76]$, contrasting effects of CD44 concerning cellular adhesion, proliferation, migration or invasion have been reported [23,27]. Our results demonstrate the importance to evaluate MW and binding state of the CD44 ligand HA in this context to clearly distinguish specific effects. The precise mechanisms of the distinction of LMW-HA and HMW-HA (being chemically identical polymers of merely different length) by CD44 is an open question. However, the application of defined presentation modes and the quantitative adhesion measurements in our study suggest different modes of CD44 dependent HA internalization and highly different strength of receptor-ligand interaction as possible reasons for the different effects of LMW-HA and HMW-HA as observed in various studies [20,62,63].

The importance to distinguish the different effects of immobilized and soluble HA is furthermore supported by the fact, that soluble HA can be found in blood and in the lymphatic circulation, as well as at degraded tissue and tumor ECM in contrast to its presentation in an immobilized 
form in the ECM [77,78]. In light of our results on partially antagonistic effects of soluble and covalently immobilized LMW-HA on invasion or proliferation for CD44+ BRO melanoma cells multiple cell behaviors can be expected for the various physiological and pathological conditions.

Besides the discussed impact of the different MW of HA and its form of presentation, one has to keep in mind, that the interaction between CD44 and HA is cell-type specific, dependent on the CD44 activation state and determined by cell-specific factors and the present splicing variant of HA receptor [68,79]. Moreover, it has been reported that cells differently respond to $\mathrm{HA}$ in $2 \mathrm{D}$ versus 3D microenvironments [80].

\section{Conclusion}

In this work we use a strategy to present HA of different MW in an immobilized and soluble manner within 3D Coll I matrices. The post-modification approach of HA functionalization after Coll I fibrillation provided no microstructural changes of Coll I network and stable HA amounts. HA was shown to bind in densely packed manner on the Coll I fibrils. These HA-modified Coll I matrices could be used to distinguish the interaction of the principal HA receptor CD44 with HA of different MW and presentation mode and the CD44 dependent impact on cellular behavior of melanoma cells. LMW-HA, but not HMW-HA, was shown to upregulate proliferation by its soluble form and to enhance invasion and adhesion by its immobilized form. In sum, our findings strongly support the notion that HA, which is found at high concentration in the tumor stroma, can promote tumor growth and invasiveness through interaction with its principal surface receptor CD44, and specific MW as well as the presentation form of HA regulate this process.

\section{Acknowledgements}

Financial support was granted by the Deutsche Forschungsgemeinschaft (DFG, grant: SCHM 2748/3-1 to SS, AN276/6-1 and SFB-TR67/B4 to UA and TP PO713/9-1, SFB-TR67/B10 and INST 268/293-1 FUGG to TP, SFB-TR67/A2, Z3 to MS).

\section{References}

[1] Dicker KT, Gurski LA, Pradhan-Bhatt S, Witt RL, Farach-Carson MC, Jia X. Hyaluronan: A simple polysaccharide with diverse biological functions. Acta Biomater 2014;10:1558-70. doi:10.1016/j.actbio.2013.12.019.

[2] Toole BP. Hyaluronan: from extracellular glue to pericellular cue. Nat Rev Cancer 2004;4:528-39. doi:10.1038/nrc1391.

[3] Nikitovic D, Tzardi M, Berdiaki A, Tsatsakis A, Tzanakakis GN. Cancer microenviroment and inflammation: Role of hyaluronan. Front Immunol 2015;6. doi:10.3389/fimmu.2015.00169.

[4] Sironen RK, Tammi M, Tammi R, Auvinen PK, Anttila M, Kosma VM. Hyaluronan in human malignancies. Exp Cell Res 2011;317:383-91. doi:10.1016/j.yexcr.2010.11.017.

[5] Rozario T, DeSimone DW. The extracellular matrix in development and morphogenesis: A dynamic view. Dev Biol 2010;341:126-40. doi:10.1016/j.ydbio.2009.10.026.

[6] Lam J, Truong NF, Segura T. Design of cell-matrix interactions in hyaluronic acid hydrogel scaffolds. Acta Biomater 2014;10:1571-80. doi:10.1016/j.actbio.2013.07.025.

[7] Schulz T, Schumacher U, Prehm P. Hyaluronan export by the ABC transporter MRP5 and its modulation by intracellular cGMP. J Biol Chem 2007;282:20999-1004. doi:10.1074/jbc.M700915200.

[8] Itano N, Kimata K. Mammalian Hyaluronan Synthases. IUBMB Life 2002;1:195-9. doi:10.1080/15216540290114478.

[9] Cyphert JM, Trempus CS, Garantziotis S. Size Matters: Molecular Weight Specificity of Hyaluronan Effects in Cell Biology. Int J Cell Biol 2015;2015:1-8. doi:10.1155/2015/563818. 
[10] Maharjan AS, Pilling D, Gomer RH. High and low molecular weight hyaluronic acid differentially regulate human fibrocyte differentiation. PLoS One 2011;6:e26078. doi:10.1371/journal.pone.0026078.

[11] Monslow J, Govindaraju P, Puré E. Hyaluronan - a functional and structural sweet spot in the tissue microenvironment. Front Immunol 2015;6:231. doi:10.3389/fimmu.2015.00231.

[12] Jordan AR, Racine RR, Hennig MJP, Lokeshwar VB. The Role of CD44 in Disease Pathophysiology and Targeted Treatment. Front Immunol 2015;6:182. doi:10.3389/fimmu.2015.00182.

[13] Ruppert SM, Hawn TR, Arrigoni A, Wight TN, Bollyky PL. Tissue integrity signals communicated by highmolecular weight hyaluronan and the resolution of inflammation. Immunol Res 2014;58:186-92. doi:10.1007/s12026-014-8495-2.

[14] Girish KS, Kemparaju K. The magic glue hyaluronan and its eraser hyaluronidase: A biological overview. Life Sci 2007;80:1921-43. doi:10.1016/j.1fs.2007.02.037.

[15] Šoltés L, Mendichi R, Kogan G, Schiller J, Stankovská M, Arnhold J. Degradative Action of Reactive Oxygen Species on Hyaluronan. Biomacromolecules 2006;7:659-68. doi:10.1021/bm050867v.

[16] Spinelli FM, Vitale DL, Demarchi G, Cristina C, Alaniz L. The immunological effect of hyaluronan in tumor angiogenesis. Clin Transl Immunol 2015;4:e52. doi:10.1038/cti.2015.35.

[17] Wu M, Cao M, He Y, Liu Y, Yang C, Du Y, et al. A novel role of low molecular weight hyaluronan in breast cancer metastasis. FASEB J 2014;1:1-9. doi:10.1096/fj.14-259978.

[18] Singleton PA. Hyaluronan regulation of endothelial barrier function in cancer. Adv. Cancer Res., vol. 123, 2014, p. 191-209. doi:10.1016/B978-0-12-800092-2.00007-1.

[19] Schmaus a, Klusmeier S, Rothley M, Dimmler a, Sipos B, Faller G, et al. Accumulation of small hyaluronan oligosaccharides in tumour interstitial fluid correlates with lymphatic invasion and lymph node metastasis. Br J Cancer 2014;111:1-9. doi:10.1038/bjc.2014.332.

[20] Stern R. Devising a pathway for hyaluronan catabolism: Are we there yet? Glycobiology 2003;13:105R - 115. doi:10.1093/glycob/cwg112.

[21] Ahrens T, Assmann V, Fieber C, Termeer CC, Herrlich P, Hofmann M, et al. CD44 is the principal mediator of hyaluronic-acid-induced melanoma cell proliferation. J Invest Dermatol 2001;116:93-101. doi:10.1046/j.1523-1747.2001.00236.x.

[22] Misra S, Heldin P, Hascall VC, Karamanos NK, Skandalis SS, Markwald RR, et al. Hyaluronan-CD44 interactions as potential targets for cancer therapy. FEBS J 2011;278:1429-43. doi:10.1111/j.17424658.2011.08071.x.

[23] Orian-Rousseau V. CD44 Acts as a Signaling Platform Controlling Tumor Progression and Metastasis. Front Immunol 2015;6:154. doi:10.3389/fimmu.2015.00154.

[24] Nam K, Oh S, Lee K, Yoo S, Shin I. CD44 regulates cell proliferation, migration, and invasion via modulation of c-Src transcription in human breast cancer cells. Cell Signal 2015;27:1882-94. doi:10.1016/j.cellsig.2015.05.002.

[25] Suzuki T, Suzuki M, Ogino S, Umemoto R, Nishida N, Shimada I. Mechanical force effect on the twostate equilibrium of the hyaluronan-binding domain of CD44 in cell rolling. Proc Natl Acad Sci 2015;112:6991-6. doi:10.1073/pnas.1423520112.

[26] Louderbough JM V, Schroeder J a. Understanding the dual nature of CD44 in breast cancer progression. Mol Cancer Res 2011;9:1573-86. doi:10.1158/1541-7786.MCR-11-0156.

[27] Marhaba R, Zöller M. CD44 in cancer progression: Adhesion, migration and growth regulation. J Mol Histol 2004;35:211-31. doi:10.1023/B:HIJO.0000032354.94213.69.

[28] Misra S, Hascall VC, Markwald RR, Ghatak S. Interactions between Hyaluronan and Its Receptors (CD44, RHAMM) Regulate the Activities of Inflammation and Cancer. Front Immunol 2015;6:201. doi:10.3389/fimmu.2015.00201.

[29] Nyga A, Cheema U, Loizidou M. 3D tumour models: Novel in vitro approaches to cancer studies. J Cell Commun Signal 2011;5:239-48. doi:10.1007/s12079-011-0132-4.

[30] Baker BM, Chen CS. Deconstructing the third dimension - how 3D culture microenvironments alter cellular cues. J Cell Sci 2012;125:3015-24. doi:10.1242/jcs.079509.

[31] Infanger DW, Lynch ME, Fischbach C. Engineered culture models for studies of tumormicroenvironment interactions. Annu Rev Biomed Eng 2013;15:29-53. doi:10.1146/annurev-bioeng071811-150028.

[32] Wolf K, te Lindert M, Krause M, Alexander S, te Riet J, Willis AL, et al. Physical limits of cell migration: Control by ECM space and nuclear deformation and tuning by proteolysis and traction force. J Cell Biol 2013;201:1069-84. doi:10.1083/jcb.201210152.

[33] Sapudom J, Rubner S, Martin S, Kurth T, Riedel S, Mierke CT, et al. The phenotype of cancer cell invasion controlled by fibril diameter and pore size of 3D collagen networks. Biomaterials 2015;52:36775. doi:10.1016/j.biomaterials.2015.02.022. 
[34] Guzman A, Ziperstein MJ, Kaufman LJ. The effect of fibrillar matrix architecture on tumor cell invasion of physically challenging environments. Biomaterials 2014;35:6954-63. doi:10.1016/j.biomaterials.2014.04.086.

[35] Acerbi I, Cassereau L, Dean I, Shi Q, Au A, Park C, et al. Human breast cancer invasion and aggression correlates with ECM stiffening and immune cell infiltration. Integr Biol (Camb) 2015;7:1120-34. doi:10.1039/c5ib00040h.

[36] Zaman MH, Trapani LM, Sieminski AL, Mackellar D, Gong H, Kamm RD, et al. Migration of tumor cells in 3D matrices is governed by matrix stiffness along with cell-matrix adhesion and proteolysis. Proc Natl Acad Sci U S A 2006;103:15-6. doi:Doi 10.1073/Pnas.0606087103.

[37] Seewaldt V. ECM stiffness paves the way for tumor cells. Nat Med 2014;20:332-3. doi:10.1038/nm.3523.

[38] Tilghman RW, Cowan CR, Mih JD, Koryakina Y, Gioeli D, Slack-Davis JK, et al. Matrix rigidity regulates cancer cell growth and cellular phenotype. PLoS One 2010;5:e12905. doi:10.1371/journal.pone.0012905.

[39] Hughes I, Blasiole B, Huss D, Warchol ME, Rath NP, Hurle B, et al. Otopetrin 1 is required for otolith formation in the zebrafish Danio rerio. Dev Biol 2004;276:391-402. doi:10.1016/j.ydbio.2004.09.001.

[40] Van Der Smissen A, Samsonov S, Hintze V, Scharnweber D, Moeller S, Schnabelrauch M, et al. Artificial extracellular matrix composed of collagen i and highly sulfated hyaluronan interferes with TGF??1 signaling and prevents TGF??1-induced myofibroblast differentiation. Acta Biomater 2013;9:7775-86. doi:10.1016/j.actbio.2013.04.023.

[41] Wang K, Andresen Eguiluz RC, Wu F, Seo BR, Fischbach C, Gourdon D. Stiffening and unfolding of early deposited-fibronectin increase proangiogenic factor secretion by breast cancer-associated stromal cells. Biomaterials 2015;54:63-71. doi:10.1016/j.biomaterials.2015.03.019.

[42] Kalbitzer L, Franke K, Möller S, Schnabelrauch M, Pompe T. Glycosaminoglycan Functionalization of Mechanically and Topologically Defined Collagen I Matrices. J Mater Chem B 2015. doi:10.1039/C5TB01737H.

[43] Pompe T, Zschoche S, Herold N, Salchert K, Gouzy MF, Sperling C, et al. Maleic anhydride copolymers - A versatile platform for molecular biosurface engineering. Biomacromolecules 2003;4:1072-9. doi:10.1021/bm034071c.

[44] Sapudom J, Rubner S, Martin S, Pompe T. Mimicking Tissue Boundaries by Sharp Multiparameter Matrix Interfaces. Adv Healthc Mater 2016. doi:10.1002/adhm.201600295.

[45] Franke K, Sapudom J, Kalbitzer L, Anderegg U, Pompe T. Topologically defined composites of collagen types $\mathrm{i}$ and $\mathrm{v}$ as in vitro cell culture scaffolds. Acta Biomater 2014;10:2693-702. doi:10.1016/j.actbio.2014.02.036.

[46] Ansorge M, Rastig N, Steinborn R, K??nig T, Baumann L, M??ller S, et al. Short-range cytokine gradients to mimic paracrine cell interactions in vitro. J Control Release 2016;224:59-68. doi:10.1016/j.jconrel.2015.12.053.

[47] Lockshin A, Giovanella BC, de Ipolyi PD, Williams LJ, Mendoza JT, Yim SO, et al. Exceptional lethality for nude mice of cells derived from a primary human melanoma. Cancer Res 1985;45:345-50.

[48] Anderegg U, Eichenberg T, Parthaune T, Haiduk C, Saalbach A, Milkova L, et al. ADAM10 is the constitutive functional sheddase of CD44 in human melanoma cells. J Invest Dermatol 2009;129:147182. doi:10.1038/jid.2008.323.

[49] Martin S, Wang H, Rathke T, Anderegg U, Möller S, Schnabelrauch M, et al. Polymer hydrogel particles as biocompatible AFM probes to study CD44 / hyaluronic acid interactions on cells. Polymer (Guildf) 2016. doi:10.1016/j.polymer.2016.02.019.

[50] Pussak D, Ponader D, Mosca S, Ruiz SV, Hartmann L, Schmidt S. Mechanical carbohydrate sensors based on soft hydrogel particles. Angew Chemie - Int Ed 2013;52:6084-7. doi:10.1002/anie.201300469.

[51] Pussak D, Behra M, Schmidt S, Hartmann L. Synthesis and functionalization of poly(ethylene glycol) microparticles as soft colloidal probes for adhesion energy measurements. Soft Matter 2012;8:1664-72. doi:10.1039/C2SM06911C.

[52] Tsai SW, Liu RL, Hsu FY, Chen CC. A study of the influence of polysaccharides on collagen selfassembly: Nanostructure and kinetics. Biopolymers 2006;83:381-8. doi:10.1002/bip.20568.

[53] Lang NR, Skodzek K, Hurst S, Mainka A, Steinwachs J, Schneider J, et al. Biphasic response of cell invasion to matrix stiffness in three-dimensional biopolymer networks. Acta Biomater 2015;13:61-7. doi:10.1016/j.actbio.2014.11.003.

[54] Yang YL, Kaufman LJ. Rheology and confocal reflectance microscopy as probes of mechanical properties and structure during collagen and collagen/hyaluronan self-assembly. Biophys J 2009;96:1566-85. doi:10.1016/j.bpj.2008.10.063. 
[55] Kreger ST, Voytik-Harbin SL. Hyaluronan concentration within a 3D collagen matrix modulates matrix viscoelasticity, but not fibroblast response. Matrix Biol 2009;28:336-46. doi:10.1016/j.matbio.2009.05.001.

[56] Servaty R, Schiller J, Binder H, Arnold K. Hydration of polymeric components of cartilage - An infrared spectroscopic study on hyaluronic acid and chondroitin sulfate. Int J Biol Macromol 2001;28:121-7. doi:10.1016/S0141-8130(00)00161-6.

[57] Masic A, Bertinetti L, Schuetz R, Chang S-W, Metzger TH, Buehler MJ, et al. Osmotic pressure induced tensile forces in tendon collagen. Nat Commun 2015;6:5942. doi:10.1038/ncomms6942.

[58] Scott JE, Quintarelli G, Dellovo MC. The chemical and histochemical properties of Alcian Blue - I. The mechanism of Alcian Blue staining. Histochemie 1964;4:73-85. doi:10.1007/BF00306149.

[59] Penney DP, Powers JM, Frank M, Willis C, Churukian C. Analysis and testing of biological stains-- The Biological Stain Commission Procedures. Biotech Histochem 2002;77:237-75. doi:10.1080/714028210.

[60] He M, Zhang H, Chen W, Dong X. Polymer physics. Oxford University Press; 2006.

[61] Toole BP. Hyaluronan promotes the malignant phenotype. Glycobiology 2002;12:37R - 42R. doi:10.1093/glycob/12.3.37R.

[62] Knudson W, Chow G, Knudson CB. CD44-mediated uptake and degradation of hyaluronan. Matrix Biol 2002;21:15-23. doi:10.1016/S0945-053X(01)00186-X.

[63] Albeiroti S, Soroosh A, De La Motte CA. Hyaluronan's role in fibrosis: A pathogenic factor or a passive player? Biomed Res Int 2015;2015:1-10. doi:10.1155/2015/790203.

[64] Murai T. Lipid raft-mediated regulation of hyaluronan-CD44 interactions in inflammation and cancer. Front Immunol 2015;6. doi:10.3389/fimmu.2015.00420.

[65] Kim Y, Kumar S. CD44-mediated adhesion to hyaluronic acid contributes to mechanosensing and invasive motility. Mol Cancer Res 2014;12:1416-29. doi:10.1158/1541-7786.MCR-13-0629.

[66] Herrera-Gayol a, Jothy S. Effects of hyaluronan on the invasive properties of human breast cancer cells in vitro. Int J Exp Pathol 2001;82:193-200.

[67] Wolny PM, Banerji S, Gounou C, Brisson AR, Day AJ, Jackson DG, et al. Analysis of CD44-hyaluronan interactions in an artificial membrane system: Insights into the distinct binding properties of high and low molecular weight hyaluronan. J Biol Chem 2010;285:30170-80. doi:10.1074/jbc.M110.137562.

[68] Yang C, Cao M, Liu H, He Y, Xu J, Du Y, et al. The high and low molecular weight forms of hyaluronan have distinct effects on CD44 clustering. J Biol Chem 2012;287:43094-107. doi:10.1074/jbc.M112.349209.

[69] Kuznetsova SA, Day AJ, Mahoney DJ, Rugg MS, Mosher DF, Roberts DD. The N-terminal module of thrombospondin-1 interacts with the link domain of TSG-6 and enhances its covalent association with the heavy chains of inter- $\alpha$-trypsin inhibitor. J Biol Chem 2005;280:30899-908. doi:10.1074/jbc.M500701200.

[70] Herishanu Y, Gibellini F, Njuguna N, Hazan-Halevy I, Farooqui M, Bern S, et al. Activation of CD44, a receptor for extracellular matrix components, protects chronic lymphocytic leukemia cells from spontaneous and drug induced apoptosis through MCL-1. Leuk Lymphoma 2011;52:1758-69. doi:10.3109/10428194.2011.569962.

[71] Bourguignon LYW. Hyaluronan-mediated CD44 activation of RhoGTPase signaling and cytoskeleton function promotes tumor progression. Semin Cancer Biol 2008;18:251-9. doi:10.1016/j.semcancer.2008.03.007.

[72] Naor D, Nedvetzki S, Golan I, Melnik L, Faitelson Y. CD44 in cancer. Crit Rev Clin Lab Sci 2002;39:527-79. doi:10.1080/10408360290795574.

[73] Elliott VA, Rychahou P, Zaytseva YY, Evers BM. Activation of c-Met and upregulation of CD44 expression are associated with the metastatic phenotype in the colorectal cancer liver metastasis model. PLoS One 2014;9:e97432. doi:10.1371/journal.pone.0097432.

[74] Morrison H, Sherman LS, Legg J, Banine F, Isacke C, Haipek CA, et al. The NF2 tumor suppressor gene product, merlin, mediates contact inhibition of growth through interactions with CD44. Genes Dev 2001;15:968-80. doi:10.1101/gad.189601.

[75] Raso-Barnett L, Banky B, Barbai T, Becsagh P, Timar J, Raso E. Demonstration of a MelanomaSpecific CD44 Alternative Splicing Pattern That Remains Qualitatively Stable, but Shows Quantitative Changes during Tumour Progression. PLoS One 2013;8:e53883. doi:10.1371/journal.pone.0053883.

[76] Branco da Cunha C, Klumpers DD, Koshy ST, Weaver JC, Chaudhuri O, Seruca R, et al. CD44 alternative splicing in gastric cancer cells is regulated by culture dimensionality and matrix stiffness. Biomaterials 2016;98:152-62. doi:10.1016/j.biomaterials.2016.04.016.

[77] Bertrand P, Girard N, Delpech B, Duval C, d'Anjou J, Dauce JP. Hyaluronan (hyaluronic acid) and hyaluronectin in the extracellular matrix of human breast carcinomas: comparison between invasive and 
non-invasive areas. Int J Cancer 1992;52:1-6.

[78] de la Torre M, Wells AF, Bergh J, Lindgren A. Localization of hyaluronan in normal breast tissue, radial scar, and tubular breast carcinoma. Hum Pathol 1993;24:1294-7. doi:10.1016/0046-8177(93)90262-F.

[79] Zöller M. CD44: can a cancer-initiating cell profit from an abundantly expressed molecule? Nat Rev Cancer 2011;11:254-67. doi:10.1038/nrc3023.

[80] Hayen W, Goebeler M, Kumar S, Riessen R, Nehls V. Hyaluronan stimulates tumor cell migration by modulating the fibrin fiber architecture. J Cell Sci 1999;112 ( Pt 1:2241-51. 